\title{
OCUPAÇÕES E RENDA DAS FAMÍLIAS DOMICILIADAS EM ÁREAS RURAIS NO ESTADO DE SANTA CATARINA NO LIMIAR DO SÉCULO XXI*
}

\author{
Lauro Mattei
}

\begin{abstract}
Resumo
Este trabalho apresenta e discute a evolução das ocupações e da renda das famílias que residem em áreas rurais no estado de Santa Catarina, tomandose como unidade de análise as famílias extensas, conforme definição constante da seção metodológica. O período de análise corresponde aos anos entre 2001 e 2005, sendo que as informações foram retabuladas a partir dos microdados das PNADs. Dentre os principais resultados obtidos, verificase que as famílias ocupadas exclusivamente em atividades agrícolas vêm reduzindo significativamente sua participação na PEA rural estadual. No entanto, constatou-se que esta queda, em parte, foi compensada pelo avanço das ocupações das famílias não-agrícolas e pelo crescimento das famílias pluriativas, fatos que associados causaram um impacto bastante positivo sobre a dinâmica do trabalho rural catarinense.
\end{abstract}

Palavras-chave: ocupação, renda, pluriatividade

Classificação JEL: J43

\section{INTRODUÇÃO}

É consenso atualmente na literatura socioeconômica que o emprego rural não pode mais ser analisado apenas a partir de sua vertente agrícola, uma vez que no espaço rural começam a ser desenvolvidas outras atividades

' Professor dos cursos de Graduação e de Pós-Graduação em Economia da UFSC. Email: mattei@cse.ufsc.br

* Artigo recebido em maio de 2008 e aceito para publicação em julho de 2008. 
que geram ocupações de caráter não-agrícola, as quais estão cada vez menos relacionadas à produção agropecuária tradicional.

Nesse contexto, emerge o debate acadêmico sobre a "nova ruralidade", o qual se expressa de diferentes maneiras. Por um lado, a visão tradicional que sempre considerou o meio rural apenas como um espaço de produção agrícola perde sua importância, uma vez que os indicadores setoriais já não conseguem mais explicar as transformações em curso, especialmente nos aspectos relativos às mudanças do processo de trabalho. Com isso, observase que, paralelamente ao enorme êxito obtido pela "Revolução Verde" em termos de expansão da produção agrícola mundial, está cada vez mais nítido o rompimento do enfoque que reduzia as funções do "rural" às atividades restritas da produção agrícola.

Por outro lado, a diversificação dos processos econômicos e sociais locais e regionais conduz a uma heterogeneidade muito grande, tanto do uso da terra como da ocupação dos territórios rurais. Decorre daí uma desarticulação dos laços tradicionais que tinham a agricultura como a única fonte de sustentação da produção e de geração de renda, o que possibilita a emergência de um diversificado processo produtivo, que vai desde a produção agropecuária tradicional até um conjunto de atividades econômicas relacionadas aos serviços, lazer, turismo, proteção ambiental e industrialização da própria produção agropecuária.

Portanto, estudos que focalizam sua atenção sobre as atividades e rendas não-agrícolas que são utilizadas pelas famílias de agricultores como recursos e estratégias para garantir sua reprodução social têm avançado significativamente nas últimas décadas, porém com pouca ênfase nos impactos dessas mudanças sobre as economias locais e, particularmente, sobre as populações rurais e o modo de vida dos agricultores familiares.

No Brasil, diversos autores vêm dando destaque às análises sobre a multifuncionalidade do espaço rural, visando apreender essas mudanças que estão em curso. Neste caso, destaca-se o grupo de pesquisadores vinculados ao "Projeto Rurbano", cujos estudos mostraram que a dinâmica do meio rural brasileiro já não pode mais ser explicada exclusivamente pelo lado da esfera

\footnotetext{
2 É um projeto temático que procura "caracterizar o novo rural brasileiro", analisando as transformações no emprego rural em onze unidades da federação (PI, RN, AL, BA, MG, RJ, SP, PR, SC, RS E DF). Tal projeto está sob a coordenação do IE/UNICAMP e conta com o apoio financeiro da FAPESP. Maiores informações encontram-se no site http:// www.eco.unicamp.br/projetos/rurbano
} 
Ocupações e renda das famílias domiciliadas em áreas rurais no Estado de Santa Catarina no limiar do século $X X \mid$

agrícola, tendo em vista a expansão de um conjunto de atividades não-agrícolas que responde cada vez mais pela dinâmica populacional rural brasileira.

Com isso, observa-se uma alteração significativa na estrutura e na composição do trabalho rural, uma vez que muitas atividades que antes eram exercidas por várias pessoas se individualizaram, liberando mão-deobra familiar. Além disso, cresceram também os índices de flexibilização e informalização do trabalho rural, tendo em vista que aumentou o número de agricultores e de seus familiares ocupados com atividades não-agrícolas.

De um modo geral, verifica-se que essas mudanças afetam mais fortemente o sistema de produção familiar, o qual vem se especializando e permitindo que as lides agrícolas sejam crescentemente asseguradas apenas pelo chefe da exploração, liberando os demais membros familiares que passam a buscar ocupação em atividades fora da agricultura. Nesta lógica, as famílias procuram se reproduzir desenvolvendo, simultaneamente, atividades agrícolas e não-agrícolas.

Este trabalho procura caracterizar a evolução da estrutura ocupacional rural no estado de Santa Catarina, a partir dos dados secundários disponíveis até o momento, analisando-se a participação dos diversos ramos de produção na geração de emprego, visando identificar o papel das ocupações não-agrícolas no contexto do emprego rural catarinense, tomando-se como unidade de análise as famílias ocupadas e domiciliadas no meio rural do referido estado.

Para tanto, o texto contém mais três seções, além desta breve introdução Na primeira delas, discutem-se os procedimentos metodológicos usados para a tabulação dos microdados das PNADs, tendo em vista a separação das informações adotada pelo conjunto de pesquisadores envolvidos com o projeto de pesquisa acima referido. Na segunda seção são analisadas as principais características do trabalho rural catarinense, destacando-se a evolução das ocupações não-agrícolas, os ramos de atividade e a composição da renda da PEA rural catarinense. Na terceira seção são apresentadas e discutidas as principais conclusões relativas às informações utilizadas.

\section{NOTAS METODOLÓGICAS}

Durante os anos noventa o IBGE introduziu diversas mudanças metodológicas em seus dois principais instrumentos de pesquisa estatística (nos 
Censos Demográficos, a partir de 1991, e nas PNADs, a partir de 1992), visando atenuar os problemas decorrentes, em grande medida, da não atualização dos perímetros urbanos.

No Censo Demográfico (CD) foram introduzidas novas categorias territoriais, além daquelas categorias que já vinham sendo adotadas há mais tempo, quais sejam: áreas urbanas, áreas urbanas isoladas, áreas rurais e áreas rurais isoladas. A partir de 1991 foram incorporadas ao CD três novas categorias domiciliares: os aglomerados rurais do tipo extensão urbana; os aglomerados rurais isolados e as áreas urbanas não-urbanizadas.

As áreas urbanas são aquelas urbanizadas dentro dos perímetros urbanos dos municípios, contando com todos os tipos de serviços. Já as áreas urbanas não-urbanizadas são aquelas áreas localizadas no âmbito do perímetro urbano, sem existência de todos os serviços e que ainda podem desenvolver atividades agropecuárias ou mesmo manterem-se ociosas. Finalmente, as áreas urbanas isoladas são aquelas que não são contíguas ao núcleo do município, embora legalmente consideradas como urbanas.

No meio rural temos as áreas rurais exclusive, que são aquelas áreas que não se enquadram em nenhum critério de serviços, aglomeração ou de densidade. São as áreas tradicionais que classicamente se diferenciam do urbano. Já os aglomerados rurais do tipo extensão urbana toma como referência o fato de que a distância do núcleo principal deve ser inferior a um quilômetro. Sinteticamente pode-se dizer que são áreas que legalmente não foram ainda incorporadas ao perímetro urbano dos municípios. Quando a distância referida for maior que um quilômetro, as áreas são classificadas como aglomerados rurais isolados. Neste último caso, definiram-se três tipos específicos para esses aglomerados: os povoados (áreas aglomeradas que não são vinculadas a um único proprietário e que possuem algum tipo de serviços com edificações permanentes); os núcleos (áreas vinculadas a um único proprietário e com independência em relação aos serviços) e os outros (áreas com ausência de serviços e sem vínculos com um único proprietário).

Com isso, atualmente os dados estatísticos gerados pelo IBGE podem ser agrupados em oito categorias, as quais ajudam a captar com maior precisão os processos de transbordamento de áreas que não são mais possíveis de serem analisadas a partir da antiga dicotomia que simplesmente separava o urbano do rural. 
Ocupações e renda das famílias domiciliadas em áreas rurais no Estado de Santa Catarina no limiar do século $X X$

Além disso, há ainda a possibilidade de separar as informações não apenas pela situação domiciliar (oito categorias domiciliares acima), mas também pela localização do município onde foi realizada a amostra, as chamadas áreas censitárias. Neste caso, as informações podem ser agrupadas em Regiões Metropolitanas, que são as informações dos municípios que fazem parte de uma região metropolitana legalmente constituída, e Regiões Não-Metropolitanas, cujas informações representam o restante dos municípios não enquadráveis na situação anterior.

A partir dessas mudanças, os microdados do CD e das PNADs retabulados pelo "Projeto Rurbano" foram analisados a partir de dois cortes estatísticos básicos. O primeiro corte separou as informações, de acordo com a área censitária, em regiões metropolitanas e não-metropolitanas, com o objetivo de isolar os efeitos das áreas metropolitanas sobre as demais áreas ${ }^{3}$.

O segundo corte organizou as informações, de acordo com a situação domiciliar, em quatro situações distintas, a saber:

a) áreas urbanas: compreende apenas as informações referentes à categoria já existente anteriormente, considerada como urbano urbanizada;

b) áreas periféricas (periferia): compreende as informações referentes às categorias urbano não-urbanizada e aglomerados rurais do tipo extensão urbana (áreas limítrofes ao perímetro urbano). Essa abertura visa captar os efeitos da extensão das áreas urbanas sobre as áreas rurais, dentro da lógica do continuum urbano-rural;

c) áreas de povoados: compreende as informações referentes às categorias urbana isolada, povoados e outros dos aglomerados rurais isolados. Essa abertura incorpora as áreas não vinculadas a um único proprietário e que possuem serviços, além das áreas urbanas não-urbanizadas, que possuem funções similares (desenvolvem atividades agropecuárias);

d) áreas rurais exclusives (rural agropecuário): compreende as informações referentes às categorias rural exclusive e os núcleos dos aglomerados rurais isolados. Essa abertura incorpora as áreas de um único proprietário onde são desenvolvidas as atividades agropecuárias, independente de possuírem ou não serviços, e delimita com maior precisão aqueles espaços onde predominam as atividades agropecuárias.

${ }^{3}$ Obviamente que esse corte só faz sentido para aqueles estados que possuem regiões metropolitanas, o que não é o caso espeć́fico de Santa Catarina. 
Finalmente, quanto ao trabalho das pessoas, deve-se registrar as mudanças introduzidas pelas PNADs na condição de ocupação. A principal delas diz respeito ao fato de que antes de 1992 este instrumento estatístico não considerava como ocupadas as pessoas que trabalhavam menos de 15 horas na semana de referência da pesquisa como trabalhadores nãoremunerados, como trabalhadores na produção para o próprio consumo ou como trabalhadores na construção para uso próprio. A partir desta data são consideradas como ocupadas as pessoas que declaram ter trabalhado pelos menos 1 hora na semana de referência nas três condições de ocupação acima citadas (trabalho não-remunerado, para o autoconsumo e na construção para uso próprio).

Esta mudança inviabiliza qualquer tipo de comparação com séries históricas anteriores. No entanto, o "Projeto Rurbano" desenvolveu uma metodologia que reconstituiu os dados da forma como usualmente as PNADs eram elaboradas, eliminando-se os efeitos das novas categorias. Com isso, a designação "PEA restrita" presente nas tabelas que fazem parte deste estudo representa uma distinção em relação aos dados publicados pelas PNADs a partir de 1992.

Outro tratamento dispensado às informações diz respeito à posição na ocupação da pessoa de referência do domicílio, com o objetivo de analisar duas variáveis importantes: a ocupação e a renda. Assim, a tipologia construída no âmbito do Projeto Rurbano separa as famílias extensas ${ }^{4}$ por posição na ocupação da pessoa de referência no domicílio em distintas categorias, conforme será discutido na seqüência. Com isso, foi construída uma unidade analítica que articula ocupação e renda do conjunto de pessoas que vivem sob um mesmo teto e que dispõe coletivamente de uma quantidade de recursos financeiros e de bens para autoconsumo.

Do ponto de vista das categorias de famílias, as informações foram organizadas em cinco categorias, como segue. Assim, o empregador compreende os casos em que uma pessoa da família se declararou como tal

\footnotetext{
${ }^{4}$ Designação criada no âmbito do "Projeto Rurbano", significando uma categoria intermediária nos dados das PNADs e representando a unidade de análise relevante. Essa unidade exclui os pensionistas, os empregados domésticos e os seus parentes e considera, além da família nuclear, os parentes desta que vivem no mesmo domicílio (mesmo que formem outro casal) e os agregados. Entende-se por agregado a pessoa que não era parente da pessoa de referência da família e nem do seu cônjuge e que não pagava hospedagem nem alimentação a membro da família.
} 
Ocupações e renda das famílias domiciliadas em áreas rurais no Estado de Santa Catarina no limiar do século $X X \mid$

na semana da pesquisa, independente da posição na ocupação dos demais membros familiares. As famílias foram classificadas como conta-própria quando um dos membros ativos declarou-se como tal, independente da posição na ocupação dos demais membros. A família foi classificada como sendo de empregados (trabalhadores assalariados) caso não existisse nem empregador e nem conta-própria e pelo menos um dos seus membros declarou exercer alguma atividade na semana de referência. Por fim, a família foi considerada como não-ocupada quando nenhum membro declarou-se ocupado na semana de referência ${ }^{5}$. A quinta categoria, na verdade, deriva de uma subdivisão das famílias empregadoras. Desta forma, as famílias dessa posição foram consideradas como empregadoras com até dois empregados (famílias com pelo menos um membro na posição de empregador e com contratação de até dois assalariados permanentes na atividade econômica) e empregadoras com mais de dois empregados (famílias com pelo menos um membro na posição de empregador e com contratação de mais de dois assalariados permanentes na atividade econômica).

A partir da construção desta categorização familiar, as famílias foram classificadas de acordo com o tipo de atividade exercida pelos seus membros na semana de referência. Assim, famílias agrícolas são aquelas em que todas as pessoas da família extensa estavam ocupadas apenas em atividades agropecuárias na semana de referência, considerando-se tanto as ocupações principais quanto as secundárias declaradas por seus membros; famílias pluriativas, aquelas em que pelo menos um dos membros da família extensa declarou exercer dupla ocupação (principal ou secundária) em atividades agrícolas ou não-agrícolas na semana de referência; e famílias não-agrícolas, aquelas em que todas as pessoas da família extensa estavam ocupadas apenas em atividades não-agropecuárias na semana de referência, tanto em termos de ocupação principal como secundária.

\footnotetext{
${ }^{5}$ As famílias foram classificadas como sendo aposentadas e/ou pensionistas quando declararam possuir uma ou mais pessoas nessa condição e quando nenhum de seus membros estivesse desempregado procurando emprego. Por outro lado, foram classificadas como "procurando emprego" quando pelo menos um de seus membros declarou ter procurado trabalho na semana de referência. Considerou-se também a situação mista quando havia pelo menos um aposentado e/ou pensionista e outro membro procurando emprego numa mesma família. Finalmente, o resíduo foi classificado como "outros não-ocupados", quando nenhuma das alternativas anteriores fosse preenchida.
} 


\section{A EVOLUÇÃO DAS OCUPAÇÕES DAS FAMÍLIAS DOMICI- LIADAS EM ÁREAS RURAIS EM SANTA CATARINA ENTRE 2001 E 2005}

Mesmo que o tratamento das informações citado na seção metodológica tenha gerado avanços no conhecimento sobre a localização domiciliar da população economicamente ativa, deve-se reconhecer que ainda restam problemas relativos à própria fonte geradora dos dados, uma vez que a PNAD não permite fazer desagregações regionais dentro de uma mesma unidade da federação, exceto naqueles casos em que a unidade da federação possui área metropolitana. Este procedimento, entretanto, não é possível em Santa Catarina porque não existem regiões metropolitanas na referida unidade da federação. Portanto, as informações utilizadas na seqüência obrigatoriamente têm que ser analisadas de forma agregada. Mesmo assim, a PNAD ainda é a mais atualizada e abrangente base de dados para se analisar as ocupações e rendas das pessoas e das famílias brasileiras.

A tabela 1 apresenta as famílias existentes em SC no ano de 2005, de acordo com o seu tipo, atividade de seus membros e situação domiciliar. Inicialmente observa-se que, do total de 1.8 milhões de famílias contabilizadas em 2005, 1.4 milhões estavam domiciliadas em áreas urbanas, o que representava aproximadamente $80 \%$ do total das famílias catarinenses. Já as famílias domiciliadas em áreas rurais respondiam por apenas $16 \%$, enquanto aquelas domiciliadas em áreas classificadas como "periferias" representavam $3 \%$. O restante diz respeito à situação domiciliar "povoado".

De um modo geral, nota-se que a grande maioria das famílias (96\%) localiza-se em áreas urbanas ou em áreas rurais exclusivas, revelando que as novas situações domiciliares introduzidas pelo IBGE em SC a partir de 1991 têm pouca contribuição às análises que procuram fugir da dicotomia tradicional que separa o rural em oposição ao urbano. Em função disso, as análises ao longo deste estudo somente farão uso dessas novas situações domiciliares quando, de fato, elas tiverem alguma expressão estatística no conjunto dos dados. 
Ocupações e renda das famílias domiciliadas em áreas rurais no Estado de Santa Catarina no limiar do século $X X \mid$

Tabela 1: Famílias extensas segundo o tipo e local de domicílio. Santa Catarina, 2005 (1.000 famílias)

\begin{tabular}{l|c|c|c|c|c|c}
\hline \multirow{2}{*}{ TIPO DE FAMÍLIA } & \multicolumn{5}{|c|}{ Não Metropolitano } & \\
\cline { 2 - 6 } & Urbanizado & Periferia & Povoado & $\begin{array}{c}\text { Rural } \\
\text { Agropec. }\end{array}$ & Sub-Total & Total \\
\hline Empregadora total & 136,4 & - & - & 33,4 & 170,4 & 170,4 \\
Agrícola & - & - & - & 18,2 & 21,1 & 21,1 \\
Pluriativo & 3,5 & - & - & 10,0 & 13,5 & 13,5 \\
Não-agrícola & 130,0 & - & - & 5,3 & 135,9 & 135,9 \\
Conta-Própria & 310,4 & 7,6 & 7,0 & 138,8 & 463,8 & 463,8 \\
Agrícola & 14,6 & - & - & 90,8 & 106,0 & 106,0 \\
Pluriativo & 17,6 & - & 3,5 & 32,2 & 53,3 & 53,3 \\
Não-agrícola & 278,1 & 7,6 & - & 15,8 & 304,5 & 304,5 \\
Empregados & 800,5 & 38,7 & 7,6 & 84,3 & 931,1 & 931,1 \\
Agrícola & 22,8 & - & - & 17,6 & 42,2 & 42,2 \\
Pluriativo & 13,5 & - & - & 13,5 & 28,1 & 28,1 \\
Não-agrícola & 764,2 & 38,7 & 4,7 & 53,3 & 860,9 & 860,9 \\
Não-ocupado na semana & 196,8 & - & 3,5 & 34,6 & 236,6 & 236,6 \\
\hline \multicolumn{1}{c}{ TOTAL } & $1.444,1$ & 48,6 & 18,2 & 291,1 & $1.802,0$ & $1.802,0$ \\
\hline
\end{tabular}

Nota: exclusive as áreas rurais dos Estados de Acre, Amapá, Amazonas, Pará, Rondônia e Roraima. “_” : representa 5 ou menos observações;

Fonte: PNAD/IBGE - Tabulações do Projeto Rurbano - Janeiro/2007.

Do ponto de vista das categorias familiares, verifica-se que as famílias de empregados respondiam por $52 \%$ do total das famílias catarinenses, enquanto as famílias de conta-própria representavam $26 \%$ do total. Ou seja, essas duas categorias respondiam por quase $80 \%$ do número total. Já as famílias classificadas como não-ocupadas na semana de referência respondiam por 13\%, enquanto as empregadoras eram responsáveis pelo percentual restante.

Em termos das tipologias adotadas (de acordo com a atividade econômica exercida), observa-se que as famílias não-agrícolas prevalecem em todos os casos, sendo seguidas pelas famílias agrícolas e, em número bem menor, pelas famílias pluriativas, independentemente da forma que essa pluriatividade seja utilizada. Este baixo percentual de participação das famílias classificadas como pluriativas indica que este fenômeno (pluriatividade) provavelmente não tenha a expressão em Santa Catarina, da mesma 
forma que vem ocorrendo outras unidades da federação onde o mesmo está sendo analisado. Este aspecto deverá ser retomado ainda na seqüência deste texto quando serão utilizadas informações específicas das áreas rurais para analisar questões centrais do presente projeto de pesquisa.

A tabela 2 apresenta a evolução do número de famílias extensas entre 2001 e 2005. Inicialmente, nota-se que ocorreram taxas anuais de crescimento significativas para todas as categorias de famílias, exceto no caso das famílias de conta-própria, uma vez que estas sofreram alterações praticamente inexpressivas entre o primeiro e o último ano da série considerada.

Tabela 2: Evolução das famílias extensas segundo o tipo e local de domicílio. Santa Catarina, 2005, (1.000 famílias).

\begin{tabular}{cccccccc}
\hline \multirow{2}{*}{ TIPO DE FAMÍLIA } & 2.001 & 2.002 & 2.003 & 2.004 & 2.005 & $\begin{array}{c}\text { Taxa 01/05 } \\
(\% \text { aa })\end{array}$ \\
\hline TOTAL & Empregadora Total & 143 & 129 & 145 & 141 & 170 & $4,5 *$ \\
Agrícola & 16 & 10 & 16 & 13 & 21 & 9,2 \\
Pluriativo & 9 & 13 & 16 & 10 & 13 & 5,9 \\
Não-agrícola & 118 & 106 & 113 & 118 & 136 & 3,9 \\
& Conta-Própria & 458 & 463 & 486 & 513 & 464 & 1,3 \\
Agrícola & 115 & 130 & 105 & 109 & 106 & $-3,3$ \\
Pluriativo & 48 & 56 & 50 & 62 & 53 & 3,2 \\
Não-agrícola & 296 & 276 & 330 & 342 & 305 & 2,7 \\
& Empregados & 820 & 851 & 848 & 877 & 931 & $2,9 * * *$ \\
Agrícola & 38 & 40 & 43 & 42 & 42 & $2,7 * *$ \\
Pluriativo & 17 & 28 & 24 & 30 & 28 & $11,0 *$ \\
Não-agrícola & 765 & 783 & 781 & 806 & 861 & $2,7 * * *$ \\
\hline TOTAL & 189 & 200 & 208 & 200 & 237 & $4,7 * *$ \\
\hline
\end{tabular}

Nota: exclusive as áreas rurais dos Estados de Acre, Amapá, Amazonas, Pará, Rondônia e Roraima. "-": representa 5 ou menos observações;

Fonte: PNAD/IBGE - Tabulações do Projeto Rurbano - Janeiro/2007.

As famílias de empregadores apresentaram taxas de crescimento da ordem de 4,5\% ao ano. Em termos absolutos isso significou um aumento de 27 mil famílias nesta condição ocupacional. Com isso, sua participação 
Ocupações e renda das famílias domiciliadas em áreas rurais no Estado de Santa Catarina no limiar do século $X X \mid$

no conjunto das categorias familiares passou de 8,5\%, em 2001, para 9,5\%, em 2005. Considerando-se a abertura acima mencionada desta categoria familiar, verifica-se que as famílias empregadoras que contratam mais de dois empregados eram 100 mil, enquanto aquelas com até dois empregados respondiam pelo restante da categoria, ou seja, 70 mil.

As famílias de empregados, que em termos absolutos têm a maior expressão no conjunto das famílias catarinenses, tiveram taxas anuais de crescimento significativas da ordem de $2,9 \%$, implicando em um acréscimo numérico de 111 mil famílias no período considerado. Com isso, a participação desta categoria aumentou de 50,5\% para 52\% entre 2001 e 2005. De algum modo, este comportamento revela que a reprodução social das famílias catarinenses está atrelada, cada vez mais, à venda da força de trabalho no âmbito das atividades econômicas.

As famílias consideradas não-ocupadas na semana de referência também apresentaram taxas de crescimento positivas da ordem de $4,7 \%$ ao ano, implicando na incorporação a esta categoria de aproximadamente 48 mil famílias. Com isso, a participação desta categoria passou de 12\% para $13 \%$ entre o primeiro e último ano da série considerada. Mais adiante será retomada a análise sobre esta condição familiar, a partir dos distintos tipos de famílias que dela tomam parte, conforme nota de rodapé que se encontra nos procedimentos metodológicos.

Finalmente, a categoria das famílias classificadas como conta-própria foi a única a reduzir sua participação no total, caindo de $28,5 \%$, em 2001, para $25,5 \%$, em 2005, embora os números absolutos se mantivessem no mesmo patamar durante o período considerado. Em grande medida, este comportamento está atrelado ao movimento das famílias desta condição que residiam em áreas rurais, conforme veremos nas tabelas subseqüentes.

Como afirmamos em passagem anterior, as novas situações domiciliares produziram poucos efeitos sobre os dados de SC, razão pela qual as duas próximas tabelas apresentarão essas mesmas tipologias familiares acima mencionadas apenas para as situações domiciliares rural e urbana.

Assim, a tabela 3 apresenta a evolução das diversas categorias familiares domiciliadas em áreas urbanas. Inicialmente, observa-se que a categoria das famílias empregadoras está fortemente concentrada nesta situação domiciliar, respondendo por $81 \%$ do total, ou seja, das 170 mil famílias 
empregadoras existentes em 2005, nada menos que 137 mil residiam em áreas urbanas. Em termos da tipologia familiar, nota-se que não se registrou a existência de famílias agrícolas, enquanto que as pluriativas são praticamente inexpressivas. Isto implica dizer que a maioria absoluta das famílias empregadoras com residência urbana é do tipo não-agrícola.

Tabela 3: Evolução das famílias extensas segundo o tipo e local de domicílio. Santa Catarina, 2005, (1.000 famílias).

\begin{tabular}{cccccccc}
\hline \multirow{2}{*}{ TIPO DE FAMÍLIA } & 2.001 & 2.002 & 2.003 & 2.004 & 2.005 & $\begin{array}{c}\text { Taxa 01/05 } \\
(\% \text { aa })\end{array}$ \\
\hline Urbana & Empregadora Total & 117 & 110 & 117 & 115 & 137 & 3,6 \\
& Agrícola & - & - & - & - & - & \\
Pluriativo & - & 6 & 5 & 4 & 4 & \\
Não-agrícola & 112 & 102 & 111 & 109 & 131 & 3,8 \\
Conta-Própria & 303 & 296 & 332 & 352 & 325 & $3,2 *$ \\
Agrícola & 6 & 11 & 6 & 8 & 15 & 15,7 \\
Pluriativo & 19 & 20 & 18 & 21 & 21 & 2,8 \\
Não-agrícola & 278 & 265 & 308 & 322 & 289 & 2,7 \\
Empregados & 741 & 765 & 770 & 795 & 847 & $3,1 * * *$ \\
Agrícola & 16 & 18 & 19 & 20 & 25 & $9,6 * * *$ \\
Pluriativo & 12 & 17 & 17 & 16 & 15 & 3,3 \\
Não-agrícola & 712 & 730 & 734 & 759 & 808 & $2,9 * * *$ \\
\hline TOTAL & 158 & 176 & 181 & 173 & 202 & $4,8 * *$ \\
\hline
\end{tabular}

Nota: exclusive as áreas rurais dos Estados de Acre, Amapá, Amazonas, Pará, Rondônia e Roraima. Fonte: PNAD/IBGE - Tabulações do Projeto Rurbano - Janeiro/2007

Já as famílias de conta-própria residentes em áreas urbanas representam $70 \%$ do total desta categoria familiar, ou seja, das 464 mil famílias de contaprópria, 325 mil residiam em áreas urbanas. Destas, apenas 15 mil foram enquadradas como agrícolas e 21 mil como pluriativas, sendo que todas as demais foram declaradas como não-agrícolas. A baixíssima presença de famílias agrícolas nesta situação domiciliar é explicada, em grande medida, pelo fato de não fazer parte da tradição catarinense as pessoas residirem em áreas urbanas e manterem suas atividades ocupacionais exclusivamente na 
Ocupações e renda das famílias domiciliadas em áreas rurais no Estado de Santa Catarina no limiar do século $X X \mid$

agricultura. Ao mesmo tempo, a possibilidade das pessoas residentes em áreas urbanas e ocupadas em atividades não-agrícolas de destinarem um tempo de sua ocupação para atividades agrícolas é bastante reduzida, decorrendo daí a baixa inserção das famílias pluriativas na categoria ocupacional das famílias de conta-própria urbanas.

As famílias de empregados residentes em áreas urbanas, por sua vez, representam $91 \%$ desta categoria familiar, ou seja, das 931 mil famílias de empregados, nada menos que 847 mil residiam no meio urbano catarinense. Destas, a maioria absoluta ( $808 \mathrm{mil}$ ) faz parte da tipologia de famílias não-agrícolas. Este comportamento também pode ser explicado pelas dificuldades que uma família de trabalhadores assalariados encontra no sentido de combinar sua ocupação assalariada urbana com outras formas de ocupação, especialmente na agricultura. Daí a baixa representatividade, tanto das famílias agrícolas de empregados, como das pluriativas.

Finalmente, deve-se mencionar que dentre as 237 mil famílias nãoocupadas na semana de referência da PNAD, 202 mil (85\%) estavam domiciliadas em áreas urbanas, sendo que a maioria delas é composta por aposentados e pensionistas, conforme veremos mais adiante.

A tabela 4 apresenta a evolução destas mesmas categorias familiares, porém residentes em áreas rurais. A categoria das famílias empregadoras, embora tendo apresentado crescimento ao longo do período analisado, é pouco expressiva no contexto rural, atingindo apenas $19 \%$ do total desta categoria. Mesmo assim, deve-se registrar que dentre os diferentes tipos de famílias, as de natureza agrícola apresentaram as maiores taxas de crescimento. Com isso, elas passaram a responder por mais de $50 \%$ dentre as tipologias adotadas.

As famílias de conta-própria residentes em área rurais mantiveram uma tendência de queda já observada na década anterior, sendo que esta redução foi significativa apenas entre as famílias exclusivamente agrícolas, enquanto que nos demais tipos familiares não se observaram alterações relevantes. Mesmo assim, os conta-própria permanecem sendo a maior categoria ocupacional, ao responder por $48 \%$ do total das famílias que residem em áreas rurais. Isto quer dizer que em praticamente a metade das famílias rurais, pelo menos um dos seus membros exercia atividades por conta-própria. Por outro lado, verifica-se que 91 mil famílias foram classificadas como exclusivamente agrícolas, ou seja, $65 \%$ das famílias de conta-própria ainda se reproduzem exclusivamente 
a partir da agricultura, fato que é possível devido ao sistema de produção agropecuária familiar que predomina em todo território catarinense.

As famílias de empregados, segundo contingente familiar mais numeroso presente no meio rural catarinense, embora não tenham apresentado tendência significativa de crescimento, revelam algumas questões relevantes. Em primeiro lugar, nota-se a expressiva participação das famílias não-agrícolas nesta categoria. Isso pode significar que, para uma parcela importante das famílias de assalariados rurais, o espaço rural é apenas um local de moradia, tendo em vista que o exercício profissional pode estar sendo realizado em outra esfera, o que é facilitado pelas proximidades das cidades e também pelos meios de transportes. Além disso, deve-se considerar também que os custos com habitação no meio urbano normalmente são mais elevados.

Tabela 4: Evolução das famílias extensas segundo o tipo e local de domicílio. Santa Catarina, 2005, (1.000 famílias).

\begin{tabular}{|c|c|c|c|c|c|c|c|c|}
\hline \multicolumn{3}{|c|}{ TIPO DE FAMÍLIA } & 2.001 & 2.002 & 2.003 & 2.004 & 2.005 & $\begin{array}{c}\text { Taxa } 01 / 05 \\
(\% \text { aa })\end{array}$ \\
\hline \multicolumn{9}{|l|}{ Rural } \\
\hline \multicolumn{3}{|c|}{ Empregadora Total } & 25 & 19 & 28 & 25 & 33 & 8,9 \\
\hline & & Agrícola & 13 & 7 & 14 & 11 & 18 & 10,8 \\
\hline & & Pluriativo & 6 & 7 & 11 & 6 & 10 & 8,7 \\
\hline & & Não-agrícola & 6 & 5 & - & 8 & 5 & \\
\hline \multicolumn{3}{|c|}{ Conta-Própria } & 155 & 167 & 154 & 161 & 139 & $-2,5$ \\
\hline & & Agrícola & 108 & 119 & 100 & 101 & 91 & $-5,0 * *$ \\
\hline & & Pluriativo & 29 & 36 & 32 & 41 & 32 & 3,5 \\
\hline & & Não-agrícola & 18 & 11 & 22 & 20 & 16 & 3,1 \\
\hline \multicolumn{3}{|c|}{ Empregados } & 79 & 85 & 78 & 83 & 84 & 0,9 \\
\hline & & Agrícola & 22 & 21 & 23 & 22 & 18 & $-3,9$ \\
\hline & & Pluriativo & 5 & 11 & 7 & 14 & 13 & $23,9 *$ \\
\hline & & Não-agrícola & 52 & 53 & 47 & 46 & 53 & $-0,9$ \\
\hline \multicolumn{3}{|c|}{ Não-ocupado na semana } & 30 & 23 & 27 & 27 & 35 & 4,1 \\
\hline \multicolumn{3}{|c|}{ TOTAL } & 290 & 294 & 287 & 297 & 291 & 0,2 \\
\hline
\end{tabular}

Nota: exclusive as áreas rurais dos Estados de Acre, Amapá, Amazonas, Pará, Rondônia e Roraima. “_”: representa 5 ou menos observações;

Fonte: PNAD/IBGE - Tabulações do Projeto Rurbano - Janeiro/2007 
Ocupações e renda das famílias domiciliadas em áreas rurais no Estado de Santa Catarina no limiar do século $X X \mid$

Uma segunda questão importante ainda relativa às famílias de empregados diz respeito ao baixo percentual de participação das famílias exclusivamente agrícolas. Esse baixo grau de assalariamento na agricultura está diretamente relacionado ao modelo de produção agropecuária que, no caso de $\mathrm{SC}$, não é dinamizado pelas relações capitalistas clássicas que colocam frente a frente os detentores do capital e os vendedores da força de trabalho.

Por último, mas não menos importante, ressalta-se o crescimento, ainda que tímido, das famílias pluriativas dentre a categoria de assalariados. Embora sua participação percentual seja baixa, em números absolutos elas mais que dobraram no período considerado, especialmente ao conseguir combinar diversas atividades, tanto na agricultura como em outros setores produtivos.

Finalmente, a categoria das famílias não-ocupadas aumentou ao longo dos anos considerados, elevando sua participação para $12 \%$ dentre todas as categorias familiares residentes em áreas rurais. No entanto, deve-se destacar que a grande maioria das famílias classificadas nesta categoria (95\%) era composta por aposentados e/ou pensionistas, revelando que o meio rural é importante espaço para as famílias de idosos que, após obter o benefício previdenciário, permanecem residindo neste local.

A tabela 5 apresenta a evolução das famílias extensas não-ocupadas na semana de referência da pesquisa. Inicialmente, observa-se que o número total aumentou a taxa significativa da ordem de $4,7 \%$ ao ano, o que significou um aumento de 47 mil famílias entre 2001 e 2005 . Neste caso, verifica-se que a categoria de famílias classificadas como aposentadas e pensionistas responde pela grande maioria. No entanto, as maiores taxas de crescimento ocorreram na categoria familiar com algum membro procurando emprego. Em parte, este crescimento último pode estar associado aos problemas que os trabalhadores encontram para se alocar produtivamente, considerando-se que a taxa geral de desemprego do país cresceu bastante na última década. 
Tabela 5: Evolução das famílias extensas não ocupadas na semana segundo o local de domicílio. Santa Catarina, 2001/2005, (1000 famílias).

\begin{tabular}{lcccccccc}
\hline \multicolumn{1}{c}{ TIPO DE FAMÍLIA } & 2.001 & 2.002 & 2.003 & 2.004 & 2.005 & $\begin{array}{c}\text { Taxa 01/05 } \\
\left(\%{ }^{\mathrm{a} a}\right)\end{array}$ \\
\hline TOTAL & 189 & 200 & 208 & 200 & 237 & 4,7 & $* *$ \\
Só pensionistas e/ou aposentados & 157 & 171 & 161 & 163 & 201 & 4,6 & $*$ \\
Pens./Apos. e procurando emprego & 9 & 15 & 20 & 17 & 17 & 16,3 & $*$ \\
Só procurando emprego & 11 & 3 & 14 & 8 & 8 & 1,4 & \\
outros não ocupados & 13 & 11 & 14 & 12 & 11 & $-1,5$ & \\
Urbano & 158 & 176 & 181 & 173 & 202 & 4,8 & $* *$ \\
Só pensionistas e/ou aposentados & 129 & 149 & 136 & 138 & 167 & 4,5 & $*$ \\
Pens./Apos. e procurando emprego & 8 & 15 & 19 & 16 & 16 & 16,3 & $*$ \\
Só procurando emprego & 10 & 3 & 13 & 8 & 8 & 3,6 & \\
outros não ocupados & 11 & 9 & 13 & 11 & 11 & 1,1 & \\
Rural & 30 & 23 & 27 & 27 & 35 & 4,1 & \\
Só pensionistas e/ou aposentados & 27 & 22 & 25 & 25 & 33 & 5,7 & \\
Pens./Apos. e procurando emprego & - & - & - & - & - & & \\
Só procurando emprego & - & - & - & - & - & & \\
outros não ocupados & - & - & - & - & - & & \\
\hline
\end{tabular}

Nota: exclusive as áreas rurais dos Estados de Acre, Amapá, Amazonas, Pará, Rondônia e Roraima. “-” : representa 5 ou menos observações;

Fonte: PNAD/IBGE - Tabulações do Projeto Rurbano - Janeiro/2007

Do ponto de vista da situação domiciliar, nota-se que a grande maioria dessas famílias localiza-se em áreas urbanas. Neste caso, deve-se mencionar o predomínio absoluto da categoria familiar composta por aposentados e pensionistas, os quais cresceram a taxas significativas, porém inferiores às taxas de crescimento daquela categoria que tinha algum membro que estava procurando emprego, sinalizando que é grande a dificuldade de obter emprego nas áreas urbanas catarinenses.

Finalmente, observa-se que também ocorreu um crescimento das famílias de aposentados e/ou pensionistas residentes em áreas rurais. Este é um processo que está em curso desde meados da década de 1990, quando o benefício da previdência social foi entendido às famílias de trabalhadores rurais de todo o país. De algum modo, a extensão deste benefício permitiu que muitas famílias, mesmo compostas apenas por pessoas idosas, perma- 
Ocupações e renda das famílias domiciliadas em áreas rurais no Estado de Santa Catarina no limiar do século $X X I$

necessem domiciliadas no meio rural catarinense, o que pode ter contribuído para arrefecer o processo de êxodo rural.

A tabela 6 apresenta a evolução das pessoas de acordo com as categorias familiares domiciliadas em áreas rurais. Do ponto de vista das famílias empregadoras, nota-se que ocorreu uma expansão absoluta das pessoas deste grupo familiar, o que é atestado pela taxa anual de crescimento de $6,8 \%$, configurando uma tendência em razão da significância do referido crescimento. No entanto, este movimento não é idêntico entre os diversos tipos familiares, uma vez que as pessoas que fazem parte das famílias nãoagrícolas apresentaram taxas anuais negativas de $0,5 \%$.

Tabela 6: Evolução das pessoas pertencentes às famílias extensas segundo o tipo e o local de domicílio. Santa Catarina, 2005, (1.000 pessoas).

\begin{tabular}{ccccccc}
\hline TIPO DE FAMÍLIA & 2.001 & 2.002 & 2.003 & 2.004 & 2.005 & $\begin{array}{c}\text { Taxa 01/05 } \\
(\% \text { aa })\end{array}$ \\
\hline Rural Agropecuário & & & & & & \\
Empregadora Total & 99 & 85 & 108 & 98 & 128 & $6,8 *$ \\
Agrícola & 49 & 33 & 50 & 40 & 66 & 8,2 \\
Pluriativo & 29 & 32 & 51 & 30 & 45 & 8,3 \\
Não-agrícola & 21 & 20 & 7 & 28 & 17 & $-0,5$ \\
Conta-Própria & 598 & 638 & 583 & 605 & 521 & $-3,3 *$ \\
Agrícola & 402 & 443 & 362 & 367 & 329 & $-5,7 * *$ \\
Pluriativo & 125 & 150 & 137 & 167 & 139 & 3,2 \\
Não-agrícola & 71 & 45 & 85 & 71 & 53 & $-1,6$ \\
Empregados & 300 & 313 & 271 & 307 & 307 & 0,2 \\
Agrícola & 74 & 76 & 81 & 82 & 64 & $-2,0$ \\
Pluriativo & 18 & 47 & 32 & 55 & 54 & $25,9 *$ \\
Não-agrícola & 208 & 191 & 158 & 170 & 189 & $-3,0$ \\
Não-ocupado na semana & 64 & 44 & 66 & 49 & 71 & 3,0 \\
\hline TOTAL & 1.062 & 1.081 & 1.028 & 1.059 & 1.027 & $-0,9$ \\
\hline
\end{tabular}

Nota: exclusive as áreas rurais dos Estados de Acre, Amapá, Amazonas, Pará, Rondônia e Roraima. "-": representa 5 ou menos observações;

Fonte: PNAD/IBGE - Tabulações do Projeto Rurbano - Janeiro/2007

Quanto à categoria familiar conta-própria, observa-se uma tendência de queda das pessoas que fazem parte deste grupo familiar, a qual se expressa 
através das taxas anuais negativas da ordem de 3,3\%, significativas aos níveis considerados e apontando claramente uma tendência. Em grande medida, este comportamento foi influenciado pela expressiva redução das pessoas pertencentes às famílias agrícolas, que sofreram redução de 22 mil pessoas entre 2001 e 2005. Este movimento pode estar indicando as dificuldades que o sistema de produção familiar encontra para manter as pessoas residindo em áreas rurais. Além destas, as famílias de conta-própria não-agrícola também tiveram redução absoluta das pessoas. Este movimento adverso nestes dois grupos familiares não conseguiu ser compensado pela expansão das pessoas que fazem parte das famílias pluriativas que, embora tenham apresentado taxas de crescimento positivas, não chegaram a constituir uma tendência, devido a não significância dessas taxas.

Finalmente, na categoria familiar de empregados residentes em áreas rurais observa-se um crescimento apenas tímido do número absoluto de pessoas. Em parte, isso decorre da redução verificada nas famílias agrícolas e também nas famílias não-agrícolas, o que confirma as dificuldades de expansão do assalariamento agrícola no meio rural catarinense, conforme já mencionadas em outras passagens deste texto. Mas o fato mais relevante é o crescimento das famílias pluriativas, que apresentaram taxas anuais significativas da ordem de $26 \%$. Este crescimento sinaliza claramente uma tendência, uma vez que as pessoas que fazem parte deste grupo familiar têm a possibilidade concreta de ampliar suas ocupações combinando atividades produtivas.

De alguma forma, este processo pode ser observado nas informações constantes da tabela 7, que apresenta apenas a evolução das pessoas economicamente ativas para os mesmos tipos de famílias residentes em áreas rurais. O primeiro aspecto a ser considerado é que o total das pessoas ocupadas, independentemente dos tipos familiares, apresentou taxas negativas da ordem de $0,4 \%$ ao ano. Mesmo não se configurando uma tendência, essa redução da taxa geral de ocupação indica as dificuldades que as pessoas que residem em áreas rurais encontram para se manter economicamente ativas.

Especificamente em relação às categorias ocupacionais, observa-se que as pessoas que fazem parte das famílias de conta-própria são a ampla maioria ( $60 \%$ do total em 2005). Entretanto, esta categoria ocupacional familiar foi a única que apresentou queda da taxa de crescimento da ordem de $2,7 \%$ ao ano, implicando em uma redução de sua participação nas ocupações rurais 
Ocupações e renda das famílias domiciliadas em áreas rurais no Estado de Santa Catarina no limiar do século $X X$

totais de $65 \%$, em 2001, para $60 \%$, em 2005. Este movimento ocorreu devido à forte retração das ocupações de pessoas das famílias agrícolas que, ao longo do período considerado, sofreram perda 37 mil pessoas. Mesmo que as pessoas ocupadas que fazem parte das famílias pluriativas e não-agrícolas tenham aumentado, este crescimento não foi suficiente para compensar a queda verificada nas ocupações de caráter estritamente agrícola.

De um modo geral, pode-se dizer que a queda das pessoas das famílias ocupadas exclusivamente em atividades agrícolas acabou afetando o desempenho da PEA rural, que apresentou redução de $0,4 \%$ ao ano no período considerado. Deve-se ressaltar, entretanto, que este impacto poderia ter sido bem maior, caso não tivesse ocorrido aumento do número de pessoas residentes em áreas rurais ocupadas em atividades não-agrícolas, ou mesmo daquelas pessoas que fazem parte das famílias pluriativas.

Tabela 7: Evolução das Pessoas Ativas (conceito restrito) das famílias extensas segundo o tipo e o local de domicílio. Santa Catarina, 2005, (1.000 pessoas).

\begin{tabular}{cccccccc}
\hline TIPO DE FAMÍLIA & 2.001 & 2.002 & 2.003 & 2.004 & 2.005 & $\begin{array}{c}\text { Taxa 01/05 } \\
\text { (\%aa) }\end{array}$ \\
\hline Região Não Metropolitana - Rural Agropecuário & & & & & & \\
Empregadora Total & 72 & 49 & 77 & 65 & 85 & 6,4 \\
Agrícola & 37 & 21 & 36 & 24 & 44 & 5,3 \\
Pluriativo & 25 & 18 & 35 & 25 & 30 & 7,1 \\
Não-agrícola & 10 & 10 & 5 & 16 & 11 & 6,4 \\
Conta-Própria & 391 & 431 & 380 & 411 & 350 & $-2,7$ \\
Agrícola & 260 & 300 & 232 & 250 & 223 & $-4,8$ \\
Pluriativo & 93 & 108 & 105 & 122 & 98 & 2,2 \\
Não-agrícola & 38 & 23 & 43 & 39 & 30 & 0,5 \\
Empregados & 132 & 145 & 136 & 151 & 147 & $2,6 *$ \\
Agrícola & 33 & 33 & 38 & 33 & 26 & $-4,7$ \\
Pluriativo & 14 & 27 & 19 & 41 & 32 & $23,2 *$ \\
Não-agrícola & 85 & 85 & 79 & 78 & 88 & 0,0 \\
Não-ocupado na semana & - & - & 3 & - & - & \\
\hline TOTAL & 597 & 625 & 596 & 628 & 583 & $-0,4$ \\
\hline
\end{tabular}

Nota: exclusive as áreas rurais dos Estados de Acre, Amapá, Amazonas, Pará, Rondônia e Roraima. “-”: representa 5 ou menos observações;

Fonte: PNAD/IBGE - Tabulações do Projeto Rurbano - Janeiro/2007 
Um movimento no sentido contrário foi observado na categoria dos empregados, que ampliou sua participação no total das ocupações rurais de $22 \%$, em 2001, para $25 \%$, em 2005 . Este aumento na participação desta categoria no total se deve, fundamentalmente, ao crescimento significativo das pessoas que fazem parte das famílias pluriativas, acompanhado pelo crescimento das pessoas das famílias não-agrícolas. De algum modo, este movimento revela que o assalariamento das famílias residentes em áreas rurais no estado de Santa Catarina tem um forte viés não-agrícola, argumento que é corroborado pelo fato de que o assalariamento exclusivamente agrícola caiu a taxas de $4,7 \%$ ao ano no período considerado.

Finalmente, deve-se mencionar que a categoria dos empregadores apresentou, em termos absolutos, um ligeiro aumento. Porém a participação desta categoria ocupacional no total das ocupações rurais é ainda baixa, permanecendo ao redor de $15 \%$ no final do período.

No âmbito da tipologia familiar adotada, deve-se registrar o comportamento das famílias pluriativas, que apresentaram aumentos do número de pessoas em todas as categorias consideradas, sendo que este crescimento foi significativo para as famílias de empregados rurais. Isso revela que a combinação de atividades agrícolas com não-agrícolas está se constituindo em uma estratégia de reprodução social das famílias que permanecem domiciliadas em áreas rurais.

É importante observar como estes diferentes tipos de ocupação das famílias geram efeitos sobre a renda rural. Antes, porém, deve-se alertar que a análise da renda a partir das PNADs apresenta limitações que podem distorcer alguns resultados. Em grande medida, as dificuldades estão diretamente relacionadas à forma de coleta dos diferentes tipos de remuneração das atividades agrícolas (renda em dinheiro e remuneração do trabalho em produtos), a qual exige do declarante uma série de cálculos que podem afetar o conteúdo das informações, levando a uma subestimação dessas rendas.

Além disso, no sistema de produção familiar há certo volume de produtos destinado ao autoconsumo que não fazem parte da renda total. Isso gera uma dificuldade maior de estimar o valor da produção destinada ao autoconsumo, o que afeta diretamente a renda da categoria das famílias de conta-própria. Com essas ressalvas, as informações das PNADs serão 
Ocupações e renda das famílias domiciliadas em áreas rurais no Estado de Santa Catarina no limiar do século $X X \mid$

utilizadas, tendo em vista tratar-se de uma das únicas fontes seqüencial de renda da população rural.

A tabela 8 apresenta a evolução da renda média das famílias residentes em áreas rurais entre 2001 e 2005, período em que a economia manteve sua estabilidade e as informações não sofrem os efeitos de deflatores usados em períodos de conversão de moeda, como foi o caso da década passada. Registre-se que o deflator utilizado foi o INPC, o mesmo que é usado pelo IBGE para comparar os resultados das PNADs entre si.

Do ponto de vista das categorias ocupacionais, nota-se a existência de um movimento linear em relação aos rendimentos, uma vez que todas as categorias familiares, exceto aquelas de não-ocupados, apresentaram elevação da renda média, sendo que apenas as famílias de empregadores e de empregados constituíram uma tendência a partir dos níveis de significância considerados.

Quanto à tipologia familiar, observa-se um movimento correlato ao anterior, tendo em vista que tanto as famílias agrícolas, as pluriativas como as não-agrícolas tiveram elevação da renda média, o que por si só é um bom indicador de desempenho das atividades econômicas no meio rural. No entanto, em termos de valores monetários, verificam-se diferenças importantes entre os diversos tipos de famílias.

Assim, verifica-se que em todas as categorias ocupacionais a renda média das famílias agrícolas é inferior as demais, chamando a atenção o caso da categoria de empregados em que a renda média das famílias agrícolas atinge a metade da renda dos outros tipos familiares. Em parte, isso realça as precárias condições de rendimento do contingente de trabalhadores que vende sua força de trabalho nas áreas rurais.

Por outro lado, a renda média das famílias pluriativas é muito superior à renda dos demais tipos de famílias consideradas, especialmente da categoria dos conta-própria e dos empregados, justamente as duas mais importantes do meio rural catarinense. Isso significa que o recurso à pluriatividade está sendo extremamente eficaz para elevar o patamar da renda média das principais categorias ocupacionais do meio rural catarinense. Em função disso, as famílias pluriativas são aquelas que detêm os maiores valores da renda média dentre todos os tipos de famílias considerados neste estudo. 
Tabela 8: Evolução da renda média dos tipos de famílias extensas segundo o local de domicílio: Santa Catarina, 2001/05, (1.000 famílias).

\begin{tabular}{|c|c|c|c|c|c|c|c|}
\hline \multirow[t]{2}{*}{$\begin{array}{l}\text { LOCAL DOMICÍLIO / } \\
\text { TIPO DE FAMÍLIA }\end{array}$} & & \multirow[t]{2}{*}{2.001} & \multirow[t]{2}{*}{2.002} & \multirow[t]{2}{*}{2.003} & \multirow[t]{2}{*}{2.004} & \multirow[t]{2}{*}{2.005} & \multirow{2}{*}{$\begin{array}{c}\text { tx cresc. } \\
(\% \text { aa.) } \\
2001 / 05^{a}\end{array}$} \\
\hline & & & & & & & \\
\hline \multicolumn{8}{|l|}{ RURALTOTAL } \\
\hline \multirow{4}{*}{ Empregadora Total } & & 1898,51 & 2236,61 & 3103,12 & 2494,57 & 2741,01 & $8,8 *$ \\
\hline & Agrícola & 1058,38 & 2010,80 & 2894,78 & 2772,88 & 2048,97 & 17,9 \\
\hline & Pluriativo & 2086,15 & 2359,31 & 3163,71 & 2686,70 & 4488,73 & $18,1 * * * *$ \\
\hline & Não-agrícola & 3372,27 & 2406,59 & 4102,17 & 1965,73 & 1823,26 & - \\
\hline \multirow[t]{4}{*}{ Conta-Própria } & & 1155,01 & 1140,47 & 1354,34 & 1349,60 & 1235,04 & 3,1 \\
\hline & Agrícola & 937,31 & 1004,19 & 1244,13 & 1184,79 & 1128,62 & $5,5 *$ \\
\hline & Pluriativo & 1545,90 & 1443,78 & 1712,18 & 1791,14 & 1575,25 & 2,6 \\
\hline & Não-agrícola & 1827,82 & 1626,00 & 1373,65 & 1300,56 & 1242,32 & $-9,5 * * * * *$ \\
\hline \multirow[t]{4}{*}{ Empregados } & & 813,61 & 981,45 & 1113,14 & 1040,84 & 1133,02 & $7,5 * *$ \\
\hline & Agrícola & 568,52 & 663,02 & 730,08 & 611,56 & 603,43 & 0,4 \\
\hline & Pluriativo & 1136,99 & 1362,07 & 1375,39 & 1322,06 & 1617,39 & $7,0 * *$ \\
\hline & Não-agrícola & 868,80 & 1019,19 & 1255,23 & 1141,66 & 1174,07 & $7,4 *$ \\
\hline \multicolumn{2}{|c|}{ Não-ocupado na semana } & 655,95 & 888,63 & 623,30 & 567,23 & 668,60 & $-4,0$ \\
\hline \multicolumn{2}{|l|}{ TOTAL } & 1068,15 & 1140,36 & 1390,66 & 1289,52 & 1314,17 & $5,5 *$ \\
\hline
\end{tabular}

Nota: exclusive as famílias sem declaração de renda e tipos de família com menos de 5 observações. estimativa do coeficiente de uma regressão log-linear contra o tempo. Neste caso, o teste $t$ indica a existência ou não de uma tendência nos dados.

$* * *, * *, *$ significam respectivamente $5 \%, 10 \%$ e $20 \%$.

Fonte: Tabulações Especiais do Projeto Rurbano, NEA-IE/Unicamp, Março 2007

Finalmente, a renda média das famílias não-agrícolas apresentou tendência de expansão em todas as categorias ocupacionais, exceto no caso dos conta-própria, onde se observou altas taxas de queda da renda. Mesmo assim, deve-se ressaltar que o patamar de renda deste tipo familiar está mais próximo do nível de renda das famílias pluriativas, demonstrando certa vitalidade das ocupações não-agrícolas no sentido de manter um nível de renda bem mais elevado que aquele oriundo das ocupações em atividades exclusivamente agrícolas.

A tabela 9 apresenta a composição da renda média familiar para as diferentes categorias ocupacionais e tipos de famílias no ano de 2005. Inicialmente, 
Ocupações e renda das famílias domiciliadas em áreas rurais no Estado de Santa Catarina no limiar do século $X X \mid$

nota-se que a renda rural total naquele ano era composta por rendimentos advindos das atividades agrícolas $(49,9 \%$; das atividades não-agrícolas $(30,1 \%)$; de aposentadorias e pensões $(16,6 \%)$; e de outras fontes $(3,4 \%)$.

Do ponto de vista das categorias consideradas, observa-se que as fontes de renda têm importâncias distintas para os vários tipos de famílias. Assim, a renda das famílias de conta-própria - a maior categoria ocupacional do médio rural catarinense - é composta majoritariamente por rendimentos advindos das atividades agrícolas $(66,3 \%)$ e por uma participação bem menos expressiva das outras fontes. Para a categoria dos empregados a situação é oposta, uma vez que a renda agrícola tem uma baixa presença na renda total (19,2\%), enquanto que a renda advinda das atividades não-agrícolas responde por $63 \%$ do rendimento dessa categoria ocupacional. Finalmente, as famílias de empregadores têm uma renda total dominada pelos rendimentos das atividades agrícolas $(65,1 \%)$, sendo bem menos expressiva a participação das outras rendas, especialmente das rendas não-agrícolas.

Tabela 9: Composição das Rendas Médias das famílias Extensas: Santa Catarina, 2005, (R\$ set. 2005).

\begin{tabular}{cccccc}
\hline \multirow{2}{*}{ LOCAL DOMICÍLIO / } & AGRÍ- & NÃO- & APOS/ & OUT & \multirow{2}{*}{ COLA } \\
TIPO DE FAMÍLIA & $\%$ & $\%$ & $\%$ & $\%$ & R $\$$ \\
\hline Rural Total & 49,9 & 30,1 & 16,6 & 3,4 & 1314,17 \\
Empregadora Total & 65,1 & 24,5 & 5,8 & 4,6 & 2741,01 \\
Agrícola & 84,6 & 0,0 & 6,7 & 8,7 & 2048,97 \\
Pluriativo & 62,9 & 31,4 & 4,7 & 1,0 & 4488,73 \\
Não-agrícola & 0,0 & 87,2 & 7,3 & 5,5 & 1823,26 \\
Conta-Própria & 66,3 & 18,1 & 13,0 & 2,6 & 1235,04 \\
Agrícola & 83,7 & 0,0 & 12,9 & 3,4 & 1128,62 \\
Pluriativo & 54,9 & 34,2 & 10,4 & 0,5 & 1575,25 \\
Não-agrícola & 0,0 & 77,3 & 19,6 & 3,1 & 1242,32 \\
Empregados & 19,2 & 63,0 & 14,9 & 2,9 & 1133,02 \\
Agrícola & 86,7 & 0,0 & 8,6 & 4,7 & 603,43 \\
Pluriativo & 41,7 & 46,8 & 7,0 & 4,6 & 1617,39 \\
Não-agrícola & 0,0 & 79,3 & 18,8 & 2,0 & 1174,07 \\
Não-ocupado na semana & 0,0 & 0,0 & 92,9 & 7,1 & 668,60 \\
\hline
\end{tabular}

Fonte: Tabulações Especiais do Projeto Rurbano, NEA-IE/Unicamp, Março 2007 
Em relação aos tipos familiares, verifica-se que as diversas fontes de renda têm um grau de participação bem distinto na composição final da renda de cada família residente em áreas rurais. Assim, as famílias agrícolas têm sua renda total fortemente condicionada pelo desempenho econômico das atividades agrícolas, muito embora algumas delas recebam influências de outras fontes de rendimento. É o caso típico das famílias agrícolas dos conta-própria, em que as rendas de aposentadorias e pensões respondem por cerca de $13 \%$ da renda total da referida categoria. Esta situação foi impulsionada a partir de meados dos anos de 1990, quando os benefícios previdenciários foram estendidos aos trabalhadores rurais. Já as rendas das famílias agrícolas de empregados e empregadores são menos influenciadas por este fator, razão que faz com que os rendimentos advindos das atividades agrícolas sejam amplamente majoritários.

As famílias não-agrícolas têm sua renda total oriunda majoritariamente das atividades econômicas executadas fora da agricultura, sendo que em todas as categorias ocupacionais este tipo de renda atinge $75 \%$ ou mais da renda familiar. No entanto, deve-se ressaltar a importância das rendas de aposentadorias e pensões que, no caso específico das famílias não-agrícolas de conta-própria, atinge aproximadamente $20 \%$ da renda desta tipologia familiar. Percentual quase idêntico é verificado também para as famílias não-agrícolas de empregados, componente que é bem menos expressivo na composição da renda das famílias de empregadores.

Já as famílias pluriativas têm sua renda total oriunda de diversas fontes de trabalhos combinados. No caso das famílias pluriativas dos conta-própria, nota-se que a renda agrícola ainda responde por quase $55 \%$ da renda total, participação que é bem menos expressiva no caso das famílias pluriativas de empregados $(41,7 \%)$. O fato comum é que a participação da renda de aposentadorias e pensões em todas as categorias ocupacionais é bem menor, comparativamente às famílias agrícolas e não-agrícolas. Ou seja, a renda de aposentadorias é bem relevante na composição da renda total das famílias pluriativas que residem em áreas rurais.

Finalmente, as famílias de não-ocupados na semana de referência da pesquisa, como não poderiam deixar de ser, têm sua renda total oriunda quase que integralmente de aposentadorias e pensões (93\%), sendo a mesma complementada pela participação de outras fontes. Aliás, essas outras 
Ocupações e renda das famílias domiciliadas em áreas rurais no Estado de Santa Catarina no limiar do século $X X \mid$

fontes têm relevância apenas na composição da renda desta categoria e na composição da renda das famílias agrícolas de empregadores.

\section{CONSIDERAÇÕES FINAIS}

As mudanças em curso na forma de ocupação da população rural podem ser melhor compreendidas quando se analisa as alocações produtivas do conjunto de membros das famílias. Neste caso, ao se agregar as informações dos indivíduos ao redor do grupo familiar, torna-se possível avaliar o comportamento de duas variáveis fundamentais nos estudos sobre a ruralidade contemporânea: a alocação da força de trabalho e as diferentes fontes de renda de todos os membros familiares.

Em termos das informações agregadas para o estado de Santa Catarina, observa-se que na última década cresceu a participação das atividades não-agrícolas na PEA rural catarinense, tanto no quesito ocupação quanto no quesito renda. Assim, em 2005 aproximadamente 30\% da PEA rural catarinense se encontrava ocupada neste setor de atividade. Num contexto de crise econômica e de desemprego crescente, essas ocupações estão sendo decisivas para amenizar os impactos negativos da queda das ocupações exclusivamente agrícolas.

Do ponto de vista da evolução das pessoas economicamente ativas que fazem parte dos diversos tipos de famílias residentes em áreas rurais, nota-se que o total das pessoas ocupadas, independentemente dos tipos familiares, apresentou taxas negativas da ordem de 0,4\% ao ano. Em grande parte, isso se deve à queda da ordem de $2,7 \%$ ao ano das pessoas que fazem parte das famílias de conta-própria. Em termos absolutos este movimento implicou na redução 37 mil pessoas ativas no período considerado. Mesmo que as famílias pluriativas e não-agrícolas tenham aumentado, este crescimento não foi suficiente para compensar a queda verificada nas ocupações de caráter estritamente agrícola.

Com isso, pode-se dizer que a queda das pessoas das famílias ocupadas exclusivamente em atividades agrícolas acabou afetando o desempenho da PEA rural, que apresentou redução de $0,4 \%$ ao ano no período considerado. Deve-se ressaltar, entretanto, que este impacto poderia ter sido bem maior, caso não tivesse ocorrido aumento do número de pessoas residentes em áreas 
rurais ocupadas em atividades não-agrícolas, ou mesmo daquelas pessoas que fazem parte das famílias pluriativas.

Desta forma, a análise referente às famílias residentes em áreas rurais no estado de Santa Catarina procura entender essas mudanças. Inicialmente, os dados revelam que quase $48 \%$ das famílias rurais ocupadas pertenciam à categoria dos conta-própria. Isso quer dizer que em praticamente a metade das famílias com domicílio rural, pelo menos um dos seus membros exercia atividade por conta-própria no ano de 2005. Do ponto de vista da tipologia familiar predominam nesta categoria as famílias agrícolas, as quais respondiam por $65 \%$ do total das famílias identificadas como conta-própria, enquanto que as famílias pluriativas representavam $23 \%$. Essas informações indicam a predominância no estado de um sistema de produção agropecuário de base eminentemente familiar, em que a produção agrícola e a produção pecuária mantêm suas respectivas importâncias, mesmo diante do fenômeno do desemprego e do crescimento das ocupações não-agrícolas, além da própria tendência de queda deste grupo familiar no contexto rural.

O segundo grupo mais numeroso são os empregados, sendo que em 2005 o mesmo somava 84 mil famílias. No entanto, nota-se que mais de $63 \%$ das famílias desta categoria desenvolviam atividades exclusivamente não-agrícolas, sugerindo que os empregados mantêm residência rural muito mais para fugir dos problemas relacionados ao meio urbano (custos aluguéis, violência, falta de habitação, etc.) do que para procurar se reproduzir enquanto atores sociais ligados à produção agropecuária.

Do ponto de vista da tipologia familiar adotada, nota-se que as famílias agrícolas apresentaram quedas significativas entre os conta-própria, além de queda também na categoria dos empregados, paralelamente a um pequeno crescimento na categoria dos empregadores. Já as famílias não-agrícolas, por sua vez, cresceram em quase todas as categorias consideradas, destacandose a expansão entre as famílias de empregados rurais.

Em relação às famílias pluriativas, nota-se que elas apresentaram aumento do número de pessoas em todas as categorias consideradas, sendo que este crescimento foi significativo para as famílias de empregados rurais. Isso revela que a combinação de atividades agrícolas com não-agrícolas está se constituindo em uma estratégia de reprodução social das famílias que permanecem domiciliadas em áreas rurais. 
Ocupações e renda das famílias domiciliadas em áreas rurais no Estado de Santa Catarina no limiar do século $X X \mid$

A expansão deste tipo de famílias no meio rural catarinense tem efeitos positivos sobre o comportamento da renda média. Neste caso, verifica-se que as famílias pluriativas têm renda muito superior à dos demais tipos de famílias consideradas, especialmente da categoria dos conta-própria e dos empregados, justamente as duas mais importantes do meio rural catarinense. Isso significa que o recurso à pluriatividade está sendo extremamente eficaz para elevar o patamar da renda média das principais categorias ocupacionais do meio rural catarinense. Em função disso, as famílias pluriativas são aquelas que detêm os maiores valores da renda média dentre todos os tipos de famílias considerados neste estudo.

Obviamente que a trajetória acima descrita contém alguns elementos que precisam ser considerados no debate que relaciona os temas das ocupações não-agrícolas com o tema da pluriatividade. Inicialmente deve-se reconhecer que o surgimento das ocupações rurais não-agrícolas provocou modificações na forma de relacionamento da sociedade com o espaço geográfico rural. No entanto, não se deve confundir as mudanças nas formas ocupacionais da população rural com processos sociais que deságuam no surgimento do agricultor pluriativo, como destacam alguns autores como Del Grossi (1998, 1999) e Graziano da Silva (1999).

Segundo Schneider (2003), esta associação indevida decorre da falta de compreensão das diferenças entre dinâmica do mercado de trabalho e o processo de transformações que ocorre na composição das famílias rurais. A separação dessas duas dimensões, de acordo com o autor, permite aos estudiosos observar que nem sempre o crescimento das ocupações rurais não-agrícolas implica em um aumento proporcional da pluriatividade das famílias com domicílio rural.

É exatamente este fenômeno que os dados sobre as ocupações das famílias rurais catarinense retratam. Por um lado, a pluriatividade não apresentou uma tendência consistente de crescimento e, por outro, as ocupações não-agrícolas cresceram numericamente nas demais categorias ocupacionais consideradas. Isso revela que a pluriatividade depende menos de alterações no mercado de trabalho e mais da dinâmica, composição e estruturação das famílias que residem em áreas rurais.

Diante deste cenário, o desenvolvimento rural não pode mais ser analisado a partir de um setor específico, mas sim ser enfocado como o somatório 
de um conjunto de atividades econômicas, em que as inter-relações entre as atividades agrícolas e as atividades não-agrícolas são cada vez maiores. Além disso, a identificação do trabalho rural restrita à esfera agrícola fica mais tênue, uma vez que a população rural tem a possibilidade de trabalhar em múltiplos setores de atividades econômicas, sejam eles localizados em áreas rurais ou em áreas urbanas.

\title{
THE OCCUPATION PROCESS AND INCOME OF RURAL FAMILIES LIVING IN THE SANTA CATARINA STATE AT THE BEGINING OF THE 21ST CENTURY
}

\begin{abstract}
This article discusses the work situation and the income of rural families in the Santa Catarina State. The characteristics of these families are described in the methodological session and the period of analysis is between 2001 and 2005. The information came from PNAD - a statistical survey by Brazilian Government. The mains results of the study are that families that are working in the agricultural sector are losing space in the economic population that live in the rural areas. At the same time, the share of pluriactivity and the non-agricultural families are increasing. The two last kinds of families are maintaining the dynamics of rural work in Santa Catarina State.
\end{abstract}

Keywords: occupation; income; multi-activity

\section{REFERÊNCIAS BIBLIOGRÁFICAS}

BAPTISTA, F. O. Famílias e explorações agrícolas. Lisboa. 1994, 27 pp.

CARNEIRO, M.J. Camponeses, Agricultores e Pluriatividade. Rio de Janeiro: Contra Capa Livraria Ltda, 1998, 228p.

DEL GROSSI, M.E. A evolução das ocupações não-agrícolas no meio rural brasileiro de 1981 a 1995. Campinas: UNICAMP, 1999. - Tese de doutorado. 
Ocupações e renda das famílias domiciliadas em áreas rurais no Estado de Santa Catarina no limiar do século $X X I$

DEL GROSSI, M. E e GRAZIANO da SILVA, J. A pluriatividade na agropecuária brasileira em 1995. In: Revista Estudos, Sociedade e Agricultura, $\mathrm{n}^{\mathrm{o}} 11$ 1998, pp.26-52.

FULLER, A. Part-time farming and the farm family: a note for future research. In: Sociologia Ruralis, v.23, n.1. 1983, pp.5-9.

FULLER, A. M. From part-time farming to pluriactivity: a decade of change. In: Rural Europe. In: Journal of Rural Studies, v.6. 1990, pp.361-373.

GRAZIANO DA SILVA, J. O novo rural brasileiro. Campinas, SP: UNICAMP.IE (Coleção Pesquisas, 1). 1999.

GRAZIANO DA SILVA, J. e DEL GROSSI, M.E. Ocupação e renda nas famílias agrícolas e rurais no Brasil, 1992/97. Relatório de pesquisa n.2. 1999, 68p.

KAGEYAMA, A. Tipologias das famílias agrícolas pluriativas. 1998, 21 p.

MARSDEN, T. Reestructuring rurality: from order to disorder in agrarian political economy. In: Sociologia Ruralis, 29. 1989, pp.312-317.

MATTEI, L. (1999). Pluriatividade e desenvolvimento rural em Santa Catarina. Campinas: UNICAMP. 1999. - Tese de Doutorado em Economia.

SACCO DOS ANJOS, F. A agricultura familiar em transição: o caso dos colonos operários de Massaranduba (SC). Pelotas: UFPEL/Editora Universitária. 1995.

SARACENO, E. The modern functions of small farm system: an Italian experience. In: Sociologia Ruralis, v.34, n.4. 1994. pp.308-328.

SCHNEIDER, S. Agricultura familiar e pluriatividade: as controvérsias do debate. 1996. $27 \mathrm{p}$. 
SCHNEIDER, S. A pluriatividade na agricultura familiar. Porto Alegre: Ed.Universidade/UFRGS. 2003.

SCHNEIDER, S. Agricultura familiar e industrialização: pluriatividade e descentralização industrial no Rio Grande do Sul. Porto Alegre: Ed.Universidade/UFRGS. 1999.

SEYFERTH, G. A colonização alemã no Vale do Itajaí-Mirin: um estudo de desenvolvimento econômico. Rio de Janeiro: Museu nacional (Dissertação de mestrado em antropologia Social). 1973.

TESTA, V.M.; NADAL, R.; MIOR, L.C.; BALDISSERA, I.T.; CORTINA, N. O desenvolvimento sustentável do oeste catarinense: propostas para discussão. Florianópolis: EPAGRI. 1996, 247p. 